\title{
Communications
}

\section{Metal-Mediated Diastereoselective Allylation Reaction of Chiral $\alpha, \beta$-Epoxy Aldehyde. Part 1}

\author{
Su Ho Park, Hee Kyoon Yoon, and Hyo Won Lee \\ Department of Chemistry, Changbuk National University, Cheongin, Changhuk 361-763, Korea. "E-mail: hwnlee(utchungbukac:kr \\ Recieived July 20, 2006
}

Key Words : Metal-mediated allylation, Laulimalide, Epoxy aldehydes

The allylmetal-aldehyde addition reaction has proven to be very uselul for the synthesis many important complex organic molecules.' The stereochemistry and reactivity of this reaction usually depend critically on the metal used. Furthermore, stereoselective allylation can be performed using allylic organometallic reagents in the presence of chiral catalysts which coordinates the metal ions.

Compared with $\alpha$-alkoxy aldehyde, the reaction of $\alpha, \beta$ cpoxy aldehyde with allylic metal has been used in a limited way. ${ }^{2}$ Generally, the nucleophilic addition to $\alpha, \beta$-epoxy aldehyde provides predominantly anti-product."

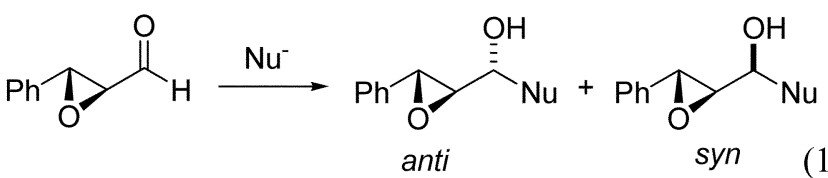

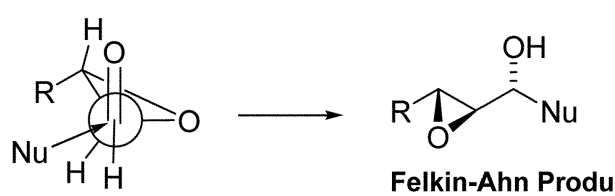<smiles>[M]O[C@@H]1[C@@H](CC)[C@H]([R])[C@@H]1CN</smiles>

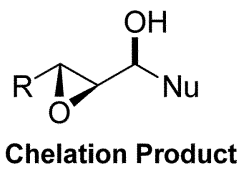

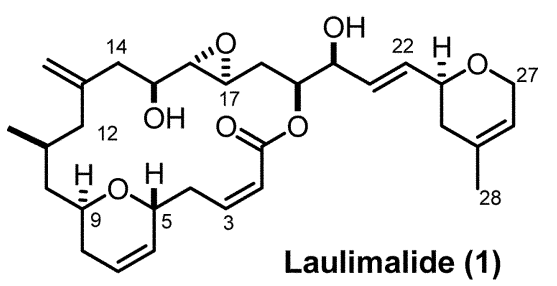<smiles>C=C(CBr)CC(C)C[C@@H]1CC=C[C@H](CC#C[PH3+])O1</smiles>

This stereoselectivity for Eq. (1) can be explained by the Felkin- $\Lambda$ hn and chelation models for anti-and syn-products, respectively.

In the course of our synthetie eflorts toward the total synthesis of laulimalide (1) we required a strategy that enables stercoselective allylation resulting in anti-product for the coupling of two synthetic fragments 2 and 3.

Metal-mediated allylation has advantages over utilization of allylmetal because of the synthetic convenience saving extra synthetic steps. Besides, in case of the indium-mediated allylation reaction, it does not require inet atmosphere or dry solvents. ${ }^{+}$With this lact in out minds, we decided to examine the indium-mediated allylation reaction between methallyl bromide and $(2 R, 3 S)$-3-phenyloxirane-2-carbaldehyde as shown in Eq. (2).

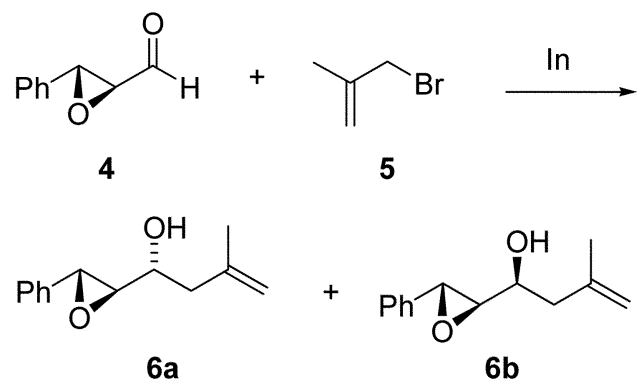

Comparing to Felkin-Ahn model, indium-mediated allylation precedes through the transition state of a chair conformation. For the chair conformational transition state,<smiles>C=C(C)C[C@H](O)[C@H]1O[C@H]1Pc1ccccc1</smiles>

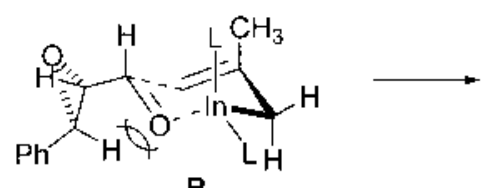<smiles>C=C(C)C[C@H](O)C1OC1c1ccccc1</smiles> 
Table 1. Indium-Mediated Allylation of Aldehyde 4

\begin{tabular}{|c|c|c|c|}
\hline Eintry & Reaction Condition ${ }^{*}$ & $\begin{array}{l}\text { Product Ratio" } \\
\quad(6 \mathbf{6}: 6 \mathbf{b})\end{array}$ & $\begin{array}{l}\text { Yield } \\
(\%)\end{array}$ \\
\hline 1 & $\mathrm{AcOH}, \mathrm{THF}, 5 \mathrm{~min}$ & $71: 29$ & 96 \\
\hline 2 & THF, 2 h & $67: 33$ & 91 \\
\hline 3 & $\mathrm{AcOH}, \mathrm{DMF}, 5 \mathrm{~min}$ & $69: 31$ & 93 \\
\hline 4 & Lil, $\mathrm{AcOH}, \mathrm{THF}, 5 \mathrm{~min}$ & $29: 71$ & 94 \\
\hline 5 & $\operatorname{lnCl} \mathrm{l}_{3}, \operatorname{Pd}\left(\mathrm{PIP}_{3}\right)_{4}, \mathrm{THF}, 2 \mathrm{~h}$ & $75: 25$ & 94 \\
\hline 6 & $\mathrm{Yb}(\mathrm{OT}):$, THF, $2 \mathrm{~h}$ & $37: 63$ & 87 \\
\hline 7 & $\mathrm{Sc}(\mathrm{OTI}), \mathrm{THF}, 2 \mathrm{~h}$ & $49: 51$ & 85 \\
\hline 8 & $(R, R)-7$, THF, 2 h & $52: 48$ & 92 \\
\hline 9 & $(S, S)-7, T H F, 2 \mathrm{~h}$ & $37: 63$ & 91 \\
\hline
\end{tabular}

"All the reactions were perlormed at room lemperature with aldehyde: bromide: $\ln =1: 1.5: 1$. "Tetermined by 'II NMR.

the simple computational calculation on the level of PM3 was perforned in order to explain the stereodiemical outcome of the indium-mediated allylation of $\alpha, \beta$-epoxy aldehyde. ${ }^{4}$ Relative stabilization encrgy of transition conformation $\Lambda$ to $\mathbf{B}$ was found to be $1.6 \mathrm{kcal} / \mathrm{mol}$. The energy differenee may come from steric and electronic effects such as Felkin-Ahn transition state. This calculation predicts antiproduct $6 \mathrm{a}$ is the major product in the reaction.

With this prediction we carried out the indium-mediated allylation under various reaction conditions as shown in Table 1 .

Fntry 1 employing the simple allylation under the acidic condition in THF provided the good result compared with entries 2 and 3 . As for entry 4, the stereochemical outcome for major product is syn. The addition of $\mathrm{Li}$ ion resulted in chelation between epoxide and aldehyde oxygens and for that reason the chelation model worked for the $s y$-product. $\mathrm{Pd}(0)$ catalytic condition showed almost same result as entry 1. For entry 6 and 7 , the addition of lanthanide Lewis acid did not give noticeable influence on the selectivity. Tentry 6 shows that using of $\mathrm{Yb}(\mathrm{OTf})$; gave insignilicant preference toward syn-product. Also we looked at the role of chiral ligands for the stereochemical selectivity using chiral 2.6bis(4-isopropyl-2-oxazolin-2-yl)pyridines(7, Pybox-i-Pr). ${ }^{5}$ Entry 8 and 9 displays daunting observation for the stereoselectivity. In these cases, the influence of the stereochemistry of the substrates seems to prevail over the chiral ligands.

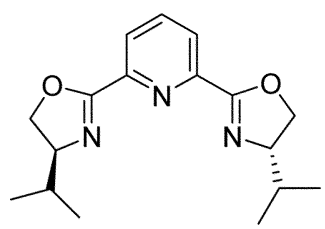

$(S, S)-7$

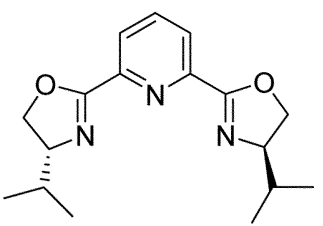

$(R, R)-7$
With these results in hand, we surveyed the further experiments with more realistic model for the total synthesis of laulimalide as shown below in Eq. (3) with chiral ligands.

The results are delineated in Table 2 . As the previous experiments, the addition of the chiral ligands does very little effects on the stereochemical selectivity. This kind of ligands is not recommendable for our experiments.

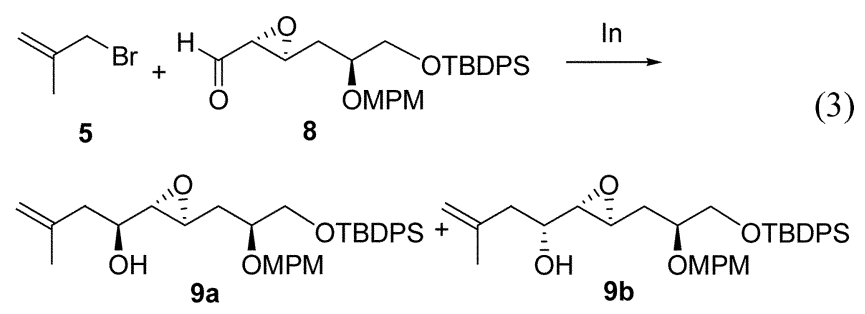

Table 2. Indium-Mediated Allylation of Aldehyde 8

\begin{tabular}{|c|c|c|c|}
\hline Гntry & Reaction Condition & $\begin{array}{l}\text { Product Ratio }{ }^{t} \\
\text { (9a:9b) }\end{array}$ & $\begin{array}{l}\text { Yield } \\
(\%)\end{array}$ \\
\hline ] & AcOl[, THIF, 5 min & $73: 27$ & 90 \\
\hline 2 & $(R, R)-7$, THIF, $3 \mathrm{~h}$ & $63: 37$ & 87 \\
\hline 3 & $\left(S_{4} S\right)-7$, THIF, $3 \mathrm{~h}$ & $49: 51$ & 85 \\
\hline
\end{tabular}

All the reactions were perfonmed at room temperature with aldehyde/ bromide In $=1: 1.5: 1$. "Delormined by ' $\mathrm{H} N \mathrm{MR}$.

So far we have demonstrated the indium-mediated allylation reaction with chiral $\alpha, \beta$-epoxy aldehyde under the various experimental conditions. We found that simple addition of acetic acid in THF is the simplest resolution for stereoselectivity of indium-mediated allylation for our systems and we need to work on with other metals for metalmediated allylation. The on-going search for other metalmediated allylation will be soon reported.

Acknowledgement. This work was supported by Chungbuk National University Grant in 2005.

\section{References}

I. (a) Modem Carbom/ Chemistry; Otera, J., Ed.; Wiley-VCH: Weinheim, 2000. (b) Scott. E.; Denınark, S. E.; Fu, J. Chem. Rev: 2003, 103. 2763-2793. (c) Nguyen, V. C.; Kim, Y.-T.: Yu. Y.-K; Kang. II.-Y. Buth. Korect Chom. Soc: 2005, 26(5),711-712. (d) Lee, J. IL.; Park, Y. S.; Nam, M. II.; Lee, S. Il.; Cho, M. Y.; Yoon. C. M. Bull. Korem Chem. Soc: 2005, 2613), 496-498. (e) Lee, I? H.; Shim, E.; Lee, K.; Seomoon, D.; Kim, S. Bull. Korem Chem. Soc: 2005, 26(1), 157-160. (f) Kang, S. W.; Heo, E. Y.: Jun, J. G; Kim, S. II. Buff. Korean Chem. Sori 2004, 25(12), 1924-1928. (g) Kang. IL. Y: Yu, Y.-K. Butl. Korecon (hem. Soc. 2004, 25(11). 1627-1628. (h) Lee, S.; Lim. C. J.; Kim, S. Bull. Korean Chem. Soc: 2004, 25(11), 1611-1612.

2. (a) Howe, G. P.; Wang, S.; Procter, G. Tetrahedron Lett. 1987, 28, 2629-2632. (b) Ipaktschi, J.; Heydari, A.; Kalinowski, H.-O. Chem. Ber. 1994, 127, 905-909. (c) Williams, D. R.; Meyer, K. G. J. Am. Chem. Soc. 2001, 123, 765-766.

3. (a) Righi, (j.; Pescatore, (j.; Bonadies, F.; Bonini, C. Tetrahedron 2001, 57, 5649-5656. (b) Righi, G.; Ronconi, S.: Boninni, C. Eur: J. Org. Chem. 2002, 1573-1577. (c) Escudier, J.-M.; Baltas, M.; Gorrichon. L. Tetrahestron 1993, 49, 5253-5266.

4. Spartan $04 \mathrm{~W}$ ver.l. 03 was used for the calculation for the transition state constraints of $2.0 \AA$ were used for the $C-C$. distances between the aldehydic carbon and the terminal allylic carbon.

5. (a) Chan, T. H.; Li, C. J. Terchetron Lett. 1991, 32, 7017-7020. (b) Chas, T. H.; Isaak, M. B. Tetrahedron Lett. 1995, 36, 89578960. (c) Paquette, I.. A.; Mitzcl. T. II. J. Am. Chem. Sor: 1996, 118, 1931-1937.

6. (a) Chelucci, (j.; Deriu, S.; Pinna, (j. A.; Saba, A.; Valenti. R. Tetrahedron: Aspmmetry 1999, 10, 3803-3810. (b) Loh, I.-I?.: Zhou, J.-R. Tetrahedron Lett. 1999, 40, 9115-9118. 